\title{
СПОСОБ ФУНДАМЕНТАЛЬНЫХ ПАРАМЕТРОВ С ПРИМЕНЕНИЕМ АБСОРБЦИОННЫХ ФАКТОРОВ НА РЕНТГЕНОВСКИХ СПЕКТРОМЕТРАХ СЕРИЙ СПЕКТРОСКАН, БРА, СРМ
}

Калинин Б.Д.

ООО «Прецизионные технологии», Санкт-Петербург, Россия

kalinin_boris@mail.ru

При реализации способа полуколичественного

DOI: 10.26902/ASFE-11_159 абсорбционных факторов были применены уравнения вида:

анализа с использованием

$$
\begin{aligned}
& C_{i}^{0}=I_{i} /\left(I_{i 0}\right) \\
& C_{i}^{(n+1)}=P_{i}^{(n)} I_{i} /\left(I_{i 0}-I_{i}+P_{i}^{(n)} I_{i}\right) P_{i}^{(n+1)}=C_{i}^{(n)}\left(J_{i 0}-J_{i}\right) /\left[J_{i}\left(1-C_{i}^{(n)}\right)\right],
\end{aligned}
$$

где $I_{i 0}$ и $I_{i}$ - экспериментальные скорости счёта аналитических линий образца с содержанием элемента $100 \%$ и анализируемого образца; $P_{i}$ - теоретические коэффициенты, зависящие от состава анализируемого образца; $J_{i}$ и $J_{i 0}$ - теоретические интенсивности аналитических линий элемента в матрице и образца с содержанием элемента $100 \%$. Для градуировки спектрометра использовались градуировочные образцы (ГО) с содержанием элемента 100\%. Основное уравнение корректировки наложения спектральных линий:

$I_{i}=I_{i}^{\ni}-a_{i}^{j} \times I_{j}$,

где $I_{i}^{\ni}$ - измеренная скорость счета аналитической линии $\mathrm{i} ; a_{i}^{j}$ - коэффициент наложения $\left(a_{i}^{j}=I_{i}^{j 100} / I_{j}^{j 100}\right.$ - измерения и расчёт в режиме градуировки); $I_{j}$ - измеренная скорость счета аналитической линии $\mathrm{j} ; I_{i}$ - скорректированная на наложение скорость счета аналитической линии i.

Процедура градуировки общая для всех типов сплавов: измеряют скорости счета аналитических линий в ГО и в контрольном образце (КО). В результате измерений получают интенсивности аналитических линий элементов в чистых образцах и интенсивности аналитических линий элементов в КО. По формуле:

$R_{J}(K O)=I_{J}(K O) / I_{i 0}$

вычисляют отношения. Используя эту формулу в анализе можно восстановить скорости счета аналитических линий элементов в ГО и учесть дрейф.

Отличие от традиционного способа фундаментальных параметров в том, что для каждого типа продуктов составлялась отдельная аналитическая программа с предварительным распознаванием типа продукта.

Способ анализа был реализован на малогабаритных кристалл-дифракционных сканирующих спектрометрах серии СПЕКТРОСКАН МАКС (СПЕКТРОСКАН МАКС-GV и СПЕКТРОСКАН МАКС-G, производства НПО «СПЕКТРОН», Санкт-Петербург) на энергодисперсионном спектрометре с полупроводниковым SDD детектором с охлаждением на основе эффекта Пельтье БРА-135 (производства НПП «БУРЕВЕСТНИК», СанктПетербург) и на сканирующих каналах (воздушном и вакуумном) спектрометра общепромышленного назначения СРМ-35 (производства НПАО «НАУЧПРИБОР», г. Орёл).

Для спектрометров серий СПЕКТРОСКАН и БРА были разработаны аналитические программы для анализа чугунов, сталей, сплавов чёрных металлов и для сплавов цветных металлов. Для спектрометра СРМ-35 кроме перечисленных типов сплавов были разработаны аналитические программы для анализа ферросплавов, руд, концентратов, шлаков и других продуктов, типичных для предприятий чёрной металлургии. 